\title{
Colecistectomia videolaparoscópica em felino com colelitíase
}

\author{
Videolaparoscopic cholecystectomy in feline with cholethiasis
}

\begin{abstract}
Rogério Luizari Guedes ${ }^{\mathrm{I}}$ João Pedro Scussel Feranti ${ }^{\mathrm{II}}$ Marília Teresa de Oliveira ${ }^{\mathrm{II}}$ Arícia Gomes Sprada ${ }^{\mathrm{II}}$ Carlos Afonso de Castro Beck ${ }^{\mathrm{III}}$ Maurício Veloso Brun ${ }^{\mathrm{II}}$
\end{abstract}

\section{- NOTA -}

RESUMO

A colelitíase, ou litíase biliar, é rara em felinos. O presente relato descreve o caso de um felino, macho, sem raça definida, com seis anos de idade que apresentava anorexia, dor abdominal, vômito e hipertermia. Ao exame ultrassonográfico de abdômen, a vesícula biliar apresentava formato irregular, paredes espessas e estruturas hiperecogênicas na região do seu colo e saída do ducto cístico, sugerindo presença de cálculos biliares. O paciente foi submetido à videolaparoscopia seguida de colecistectomia. Após sete dias, o animal obteve alta hospitalar e, aos 60 dias de pósoperatório, não demonstrou recidiva dos sinais clínicos.

Palavras-chave: laparoscopia, obstrução, doença hepatobiliar, gatos.

\section{ABSTRACT}

Cholelithiasis, or gallstones, is rare in cats. This report describes the case of a six years-old mongrel cat male that had anorexia, abdominal pain, vomiting and hyperthermia. The abdominal ultrasound revealed a gallbladder with irregular shape andhyperechogenic structures, in the gallbladder's neck and in the output of the cystic duct, suggesting gallstones. The patient was undergone to a laparoscopic cholecystectomy. The animal was hospitalized for a week and after sixty days the owner no longer report clinical signs previously presented.

Key words: laparoscopic, cholelithiasis, hepatobiliary disease, cats.

As doenças que mais afetam o sistema biliar dos felinos estão relacionadas aos processos obstrutivos, aos distúrbios neoplásicos, à infecção pelo Platynosomumconcinnum e aos processos inflamatórios como colecistite, coledoquite e complexo colangite/colangio-hepatite (CCCH) (GRACE, 2004). A ocorrência de colelitíase em cães e gatos é rara (ROTHUIZEN, 2001) e pode ser encontrada nos ductos biliares intrahepáticos (hepatolitíase), ducto cístitico, esfíncter de Oddi ou na vesícula biliar (colecistolitíase), sendo a colecistolitíase a mais comum (AGUIRRE, 2007). O desenvolvimento da litíase é decorrente de estase biliar, inflamação ou infecção (SCHAFER, 1993).

A colangite, a colecistite, a colelitíase, a obstrução do ducto cístico e as neoplasias ou os traumas da vesícula biliar dos felinos podem ser tratadas de forma cirúrgica, realizando a colecistectomia (BRIGHT \& BAUER, 1994. Para os acessos cirúrgicos referentes à colecistectomia, utiliza-se a cirurgia convencional, através da abordagem pela linha média ventral (FOSSUM et al., 2005), e a laparoscópica, na qual tradicionalmente se empregam três a quatro portais em triangulação (FREEMAN \& KOLATA, 1998).

Considerando que a realização de colecistectomia em felinos é raramente trazida na literatura veterinária, o presente trabalho tem como objetivo relatar o tratamento bem sucedido de colecistite decorrente de colelitíase por videolaparoscopia em um gato.

Um felino, macho, sem raça definida, com seis anos de idade, foi atendido por demonstrar anorexia e vômito (dois episódios por dia) havia mais de três dias. O proprietário relatoumudanças no

\footnotetext{
IMédico Veterinário autônomo, Curitiba, PR, Brasil.

IIPrograma de Pós-graduação em Cirurgia Veterinária, Universidade Federal de Santa Maria (UFSM), 97105-900, Santa Maria, RS, Brasil. E-mail: mauriciovelosobrun@hotmail.com.*Autor para correspondência.

IIIPrograma de Pós-graduação em Ciências Veterinárias, Universidade Federal do Rio Grande do Sul, (UFRGS), Porto Alegre, RS, Brasil. Recebido 11.04.13 Aprovado 17.09.13 Devolvido pelo autor 18.01.14 CR-2013-0500.R4
} 
comportamento do animal, o qual se tornou apático e com sinais de dor à manipulação abdominal.

Ao exame físico, o paciente encontravase com grau de desidratação estimado em 5\%, mucosas congestas, tempo de preenchimento capilar de 2s, dor à palpação abdominal em região epigástrica direita e temperatura retal de $40^{\circ} \mathrm{C}$. Foi realizado exame hematológico e bioquímico, não se evidenciando alterações nos valores considerados fisiológicos para felinos.

A ultrassonografia abdominal evidenciou fígado com dimensões aumentadas, contornos regulares, ecotextura grosseira e parênquima heterogêneo de ecogenicidade mista. A vesícula biliar apresentava formato irregular e as paredes espessas, e conteúdo com estruturas hiperecogênicas (Figura 1C), provocando sombra acústica na região do seu colo e saída do ducto cístico, sugestivo de cálculos biliares (Figura 1D). O ducto cístico e o ducto biliar comum apresentavam seu trajeto alterado com regiões espessadas.

Frente às observações clínicas e ultrassonográficas, optou-se pela realização de avaliação videolaparoscópica da vesícula biliar para confirmação do diagnóstico e realização do tratamento. Através do recurso videocirúrgico, foi possível ratificar a suspeita clínica de colelitíase e observar a viabilidade do ducto biliar comum, possibilitando a colecistectomia pelo mesmo acesso.

O paciente foi submetido à medicação préanestésica utilizando acepromazina $0,2 \%\left(0,05 \mathrm{mgkg}^{-1}\right.$, IM) e butorfanol (0,2 $\mathrm{mgkg}^{-1}$, IM). Para profilaxia

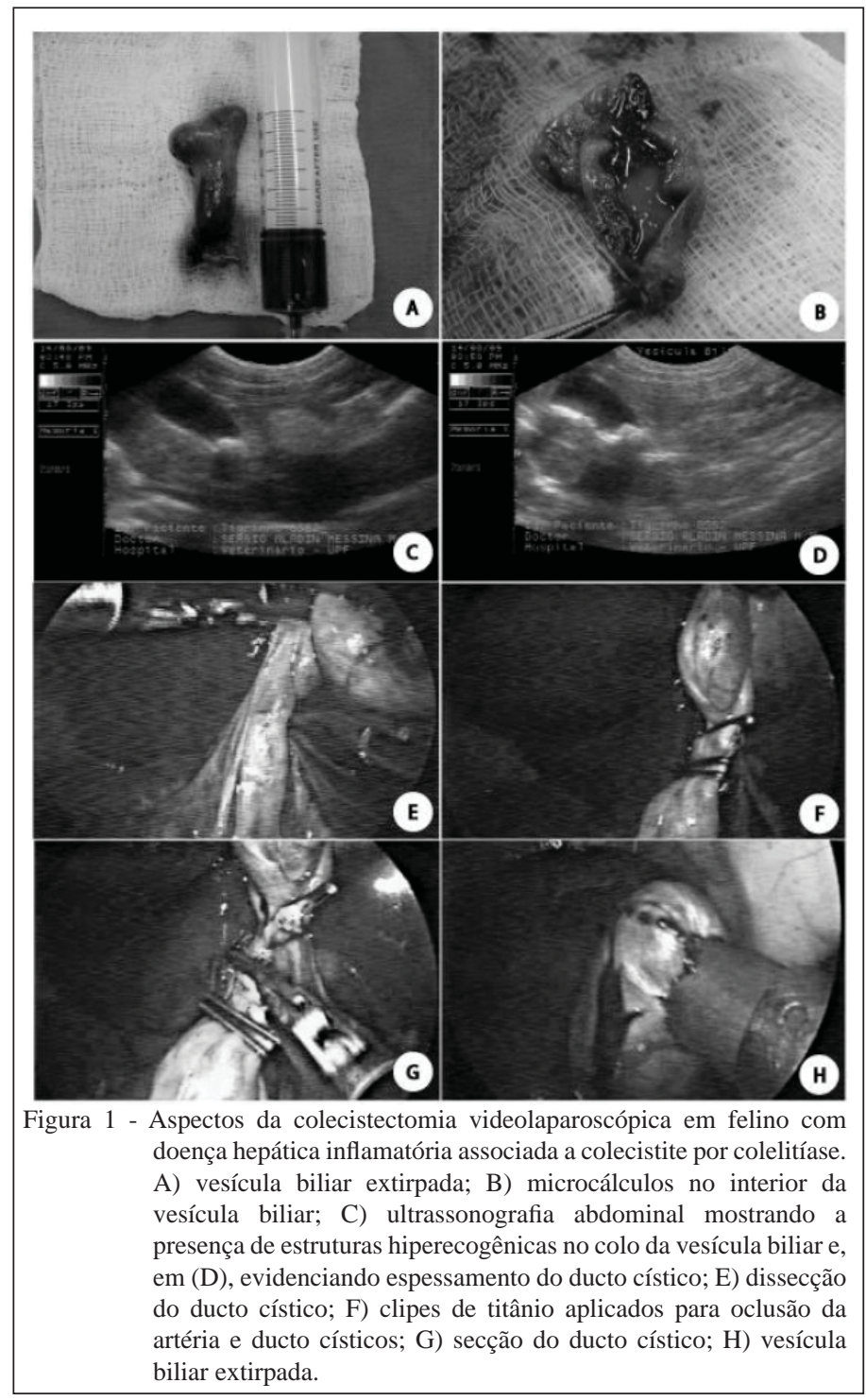

Ciência Rural, v.44, n.4, abr, 2014. 
antimicrobiana, foi administrada cefazolina sódica a 20\% (20 $\left.\mathrm{mgkg}^{-1}, \mathrm{IV}\right)$. Após 30 minutos, realizouse a indução anestésica com propofol (5mgkg-1, IV), seguido da entubação orotraqueal, utilizando sonda 3,5mm. O animal foi colocado na mesa cirúrgica em posição de céfalo-aclive, em angulação de aproximadamente $30^{\circ}$. A manutenção anestésica foi realizada com isofluorano 1\% em oxigênio a 100\%, por meio de vaporizador universal em um fluxo de 1,5 $\mathrm{Lmin}^{-1}$. A fluidoterapia foi instituída utilizando um padrão de $10 \mathrm{mlkg}^{-1} \mathrm{~h}^{-1}$ com solução de $\mathrm{NaCl}$ a $0,9 \%$.

Para o procedimento videolaparoscópico, realizou-se incisão de pele de aproximadamente $6 \mathrm{~mm}$ na região pré-umbilical da linha média ventral, à distância aproximada de $1 \mathrm{~cm}$ da cicatriz umbilical. Pela técnica aberta, foi inserido o primeiro trocarte de $5 \mathrm{~mm}$, obtendo-se a insuflação de $\mathrm{CO}_{2}$ medicinal $(1 \mathrm{~L} /$ min) até alcançar pressão intracavitária de $12 \mathrm{mmHg}$. Sob visualização endoscópica, utilizando endoscópio de $0^{\circ}$ e $5 \mathrm{~mm}$ acoplado à microcâmera e à fonte de luz, elegeram-se as duas outras posições para introdução dos outros portais. A segunda punção foi realizada na parede abdominal esquerda, utilizando trocarte de $10 \mathrm{~mm}$. O terceiro acesso foi obtido na parede abdominal direita, com portal de $5 \mathrm{~mm}$. Em seguida, realizou-se a inspeção da cavidade abdominal, fígado e do sistema extra-hepático, evidenciandose a presença de vesícula repleta e com contornos irregulares. O ducto biliar comum apresentava-se sem alterações, porém a região do colo vesicular e do ducto cístico demonstrava invasão parenquimática e espessamento. Os ductos hepáticos estavam preservados e com diâmetros normais para a espécie. Após a confirmação das alterações na vesícula biliar e ducto cístico, optou-se pela realização da colecistectomia videolaparoscópica.

Com uma pinça de preensão passada pelo portal direito, elevou-se a vesícula biliar para facilitar o acesso ao colo vesical. No outro portal, foi utilizada uma pinça Kelly e, então, partiu-se em desfazer as aderências ao redor do ducto cístico (Figura 1E). Após a adesiólise e dissecação do ducto cístico, foram aplicados três clipes de titânio (Figura 1F), abrangendo essa estrutura e os vasos associados, sendo mantido dois desses implantes proximalmente à junção do ducto biliar comum. Após a secção do ducto cístico (Figura 1G), partiu-se para liberação da vesícula biliar das bordas hepáticas através de divulsão romba com uma tesoura de Metzenbaum. Foi aplicado outro clipe para a oclusão de canalículos biliares, provenientes do lobo medial direito, para permitir a liberação da vesícula biliar. Essa estrutura foi então retirada através da ferida produzida para o trocarte de 10mm (Figura 1H). Após a verificação de ausência de hemorragia, a cavidade foi desinsuflada e as feridas de acesso suturadas, sendo na musculatura utilizado o padrão Sultan e fio poligalactina 910 2-0. Na pele, optou-se pelo padrão interrompido simples e fio de náilon monofilamentar 4-0. A vesícula biliar extirpada apresentava-se macroscopicamente de forma globosa (Figura 1A), com as paredes espessadas, e seu conteúdo era composto de microcálculos (Figura 1B).

Após a recuperação anestésica, foi administrado o cetoprofeno (1mg $\mathrm{kg}^{-1}$, IM, s.i.d, por três dias). A terapia medicamentosa constituiuse de amoxicilina $\left(11 \mathrm{mgkg}^{-1}\right.$, VO, b.i.d, por 15 dias), metronidazol (12,5mgkg-1, VO, b.i.d, por 10 dias), ácido ursodesoxicólico (15 $\mathrm{mgkg}^{-1}$, VO, s.i.d, por 15 dias), lactulose $(2,5 \mathrm{~mL}$, VO, t.i.d, por sete dias $)$, metoclopramida $\left(0,2 \mathrm{mgkg}^{-1}\right.$, SC, t.i.d, por sete dias), ranitidina $\left(2,5 \mathrm{mgkg}^{-1}\right.$, IV, b.i.d, por 15 dias) e tramadol $\left(2 \mathrm{mgkg}^{-1}, \mathrm{SC}\right.$, t.i.d, por quatro dias). O animal ficou internado por uma semana até a redução dos valores das suas enzimas hepáticas. $\mathrm{Na}$ alta hospitalar, foi recomendada dieta especial a base de ração terapêutica hipoproteica. Até 60 dias de pósoperatório, o paciente não havia apresentado sinais de recidiva dos sinais clínicos antes apresentados.

O tempo cirúrgico foi de 110minutos sem complicações transoperatórias, ou pós-operatórias associadas à operação. Contudo, a única condição diferenciada nesse caso foi a necessidade de se aplicar clipes em dois canalículos hepáticos (um clipe para cada canalículo) provenientes do lobo hepático medial direto, que estavam no plano de dissecção e que desembocavam diretamente no ducto cístico. No pós-operatório imediato, o animal apresentou anorexia por três dias e dois episódios de vômito. Após o tratamento clínico durante esse período, passou a ingerir a dieta pastosa, por mais quatro dias, quando obteve alta hospitalar.

Em felinos, EICH \& LUDWIG (2002), em estudo realizado com nove animais com obstrução de ducto cístico, em cinco deles, foi realizada a colecistectomia convencional e essa técnica mostrou-se também eficaz do ponto de vista clínico e cirúrgico. Contudo, a abordagem videolaparoscópica para tratamento de colecistite em gatos ainda é pouco explorada (STEDILE, 2006), mas deve ser estudada, pois poderá estar associada às vantagens descritas para humanos. A videolaparoscopia permitiu visualizar com muita clareza o plano de dissecção, incluindo a necessidade de ligadura e secção de dois canalículos biliares que se encontravam no plano de clivagem.

A abordagem videolaparoscópica das estruturas do sistema biliar extra-hepático se 
mostra efetiva para a confirmação do diagnóstico da doença hepática inflamatória em gatos, bem como para realização do seu tratamento através da colecistectomia, utilizando-se três portais abdominais para o acesso.

\section{COMITÊ DE ÉTICA E BIOSSEGURANÇA}

Declaração dos autores: O relato foi executado com animal atendido na rotina clínica do Hospital Veterinário da Universidade de Passo Fundo - RS - e não foi parte de qualquer projeto, sendo apenas um relato de caso clínico, então os autores ficam a disposição para quaisquer esclarecimentos futuros sobre o trabalho.

\section{REFERÊNCIAS}

AGUIRRE, A.L. et al. Gallbladder disease in Shetland Sheepdogs: 38 cases (1995-2005). Journal of the American Veterinary Medical Association, v.231, p.79-88, 2007.

BRIGHT, R.M; BAUER, M.S. Surgery of the digestive system. In: SHERDING, R.G. The cat: diseases and clinical management. 2 ed. New York: Churchill Livingstone, 1994. V.1, p.1389-1391.
EICH, C.S; LUDWIG, L.L. The surgical treatment of cholelithiasis in cats: a study of nine cases. Journal of the American Animal Hospital Association, v.38, p.290-296, 2002.

FOSSUM, T.W. et al. Cirurgia do sistema biliar extra-hepático. In:__ Cirurgia de Pequenos Animais. 2 ed.São Paulo: Roca, 2005. V.1, p.476-479.

FREEMAN, L.J; KOLATA, R.J. Minimally invasive surgery of the liver and biliary system. In: FREEMAN, L.J. Veterinary Endosurgery. Saint Louis: Mosby, 1998. V.1, p.156-158.

GRACE, S.F. Doença hepática inflamatória (hepatite). In: NORSWORTHY, G.D. et al. O paciente felino: tópicos essenciais de diagnóstico e tratamento. São Paulo: Manole, 2004. V.1, p.363-364.

SCHAFER, J. et al. Hepatic blood volume responses and compliance in cats with long term bile duct ligation. Hepatology, v.18, p.969-977, 1993.

STEDILE, R. et al.Colecistectomia laparoscópica em felino com colelitíase - relato de caso. In: Anais do Congresso Brasileiro da Anclivepa, 2006, Vitória, ES. V.1, p.42.

ROTHUIZEN, J. Hepatopatias e doenças do trato biliar. In: DUNN, J.K. Tratado de medicina de pequenos animais. São Paulo: Roca, 2001. V.1, p.443-493. 